\title{
Respiration during the First Six Months of Life in Normal Infants. III. Computer Identification of Breathing Pauses
}

\author{
TOKE HOPPENBROUWERS," "' JOAN E. HODGMAN, KAZUKO ARAKAWA, RONALD HARPER, AND \\ M. B. STERMAN \\ Newborn Division of the Los Angeles County/University of Southern California Medical Center; Department of \\ Pediatrics. University of Southern California School of Medicine; Sepulveda Veterans Hospital; Departments of \\ Anatomy. Psychiatry, and the Brain Research Institute. University of California. Los Angeles, USA
}

\begin{abstract}
Summary
The first objective of this study was to quantify computeridentified breathing pauses in excess of two sec duration in relation to sleep states. The second objective was to examine which respiratory variables at one wk and one month of age predicted total apnea at 2 and 3 months of age.

Short apnea (2 to $5 \mathrm{sec})$ were abundant in recordings of normal infants during the first one-half year of life. Apnea between 6 and 9 sec should be considered normal, whereas apnea in excess of 9 sec occurred most frequently in the first wk of life and declined sharply thereafter. Recording duration substantially affected apnea counts. Apnea at later ages could not be reliably predicted from recordings during the first wk of life.
\end{abstract}

\section{Speculation}

Short breathing pauses in QS during the age span under investigation are probably inversely related to breathing rate and caused by the same mechanism responsible for the decline in rate. The change in breathing pauses over age in AS can probably be accounted for by two sources of variance, first, the decline in rate and second, rate-independent developmental changes in control of ventilation during $\mathbf{A S}$.

An estimated 7000 to 8000 infants die each year in the United States of sudden infant death syndrome (SIDS) (1). Whereas apnea and short breathing pauses have been implicated in the etiology of SIDS $(3,10,12)$, the significance of these respiratory phenomena is still a matter of conjecture. The vast majority of infants succumbing to SIDS are healthy term infants who die suddenly without any prodromal symptoms. Moreover, the prevalence of short apnea in normal infants has generally not been appreciated.

Steinschneider (11) is exploring the utilization of a composite laboratory risk score to identify neonates at increased risk to subsequently die of SIDS. This score incorporates a number of sleep variables and a count of apneic pauses $\geq 2 \mathrm{sec}$, based on a $\mathrm{I}$ to 3 -hr recording. A previous report in normal infants (7) was restricted to central apnea $\geq 6 \mathrm{sec}$ identified through visual analysis of 12 -hr recordings. In the present study, we report the density of breathing pauses in excess of $2 \mathrm{sec}$ duration identified by computer. This study also examines the question whether or not apnea in the newborn period predict counts at later ages. whether quiet sleep (QS) apnea densities predict active sleep (AS) apnea densities, and whether the incidence of short pauses are correlated with the incidence of longer breathing pauses.

\section{MATERIAL AND METHODS}

\section{MATERIAL AND MONITORING PROCEDURES}

Twenty-five neurologically normal infants participated in this study. The mean and standard deviation of gestational age. Apgar scores, birth weights, and age at the time of monitoring are provided in Table 1. Infants were full term, and weights were appropriate for gestational age according to the intrauterine growth curve of Usher and McLean (14). Participants in all groups were volunteers, and informed consent was obtained.

Each infant was admitted at 5:00 PM to the sleep laboratory for 12-hr all night monitoring sessions during the first wk of life and at $1,2,3,4$, and 6 months of age. The infants were fed during preparation for monitoring and application of electrodes. A demand feeding schedule was followed, and in several instances, the infants were breast fed. Arm restraints were applied before the initiation of recording. Monitoring was carried out in a darkened room adjacent to the room containing recording equipment. Room temperatures ranged between 22 and $30^{\circ} \mathrm{C}$. The infants were placed in a supine or side-lying position and observed continuously with the use of a low illumination television camera and monitor. Behaviors such as closing or opening of eyes, startles, crying, and nursing interventions were charted on the polygraph paper.

\section{RECORDING METHOD}

The sleep variables recorded included two electroencephalogram derivations, a chin electromyogram, and eye movements. Thoracic or abdominal excursions were monitored by impedance pneumography. In addition, a Beckman $\mathrm{pCO}_{2}$ monitor sampled expired gas through a miniature cannula taped under the infant's nostrils. To adjust for the time lag inherent to this instrument, the phase of respiration was simultaneously detected with a thermistor placed into one arm of the cannula. The electrocardiogram was recorded with two disposable electrodes placed symmetrically beneath the clavicles. A ground electrode was applied above the umbilicus. Additionally, a skin temperature probe was applied to the abdomen below the right costal margin. Electrodes on the mattress surface under the crib sheet registered the infant's gross body movements (5). Data were recorded on a 16-channel Honeywell analog tape recorder together with an IRIG E time code.

\section{DATA ANALYSIS}

The 12 -hr recordings were coded by trained observers according to established state criteria (6). Each min of the record was classified as either awake, QS, is, or indeterminate state (IN). 
Data on the analog tapes were processed by a PDP- 12 computer (4). The respiratory signal was digitized at eight samples per sec and stored on industry-compatible magnetic tape together with digitized values of other physiologic measures. The $\mathrm{pCO}_{2}$ signal was used for this analysis because movements of the infant did not affect the signal quality. Peaks and troughs of breaths were measured by a peak-sensing program developed by Mason et al. (9). A computer package was developed to identify breathing pauses equal to or longer than $2 \mathrm{sec}$ duration in each sleep state. Measurements were made from the peaks of the $\mathrm{CO}_{2}$ tracing, and breathing intervals were therefore measured differently from those identified visually. Figure 1 provides three respiratory tracings, an estimate of the length of a breathing pause based upon criteria used for visual identification of apnea (7), and the computerderived breathing pause. The latter technique, although reliable, tends to overestimate the duration of a pause by $1 \mathrm{sec}$ compared to visual inspection (7). The minimum interval of $3 \mathrm{sec}$ was selected so as to be comparable to an estimate of a 2-sec breathing pause measured visually. Duration categories will be arbitrarily adjusted to visual criteria: short, 2, 3, 4 and 5 sec duration; medium, between 5 and 9 sec duration; and long, equal to or in excess of $10 \mathrm{sec}$. Inasmuch as the $\mathrm{pCO}_{2}$ signal was used, this computer strategy did not differentiate between but included central, mixed, and obstructive pauses. The absolute number of breathing pauses per state was integrated with the total number of minutes spent in each state, and a density score was calculated with the aid of an IBM 360. Data from the first 19 infants were submitted to an analysis of variance to examine developmental trends. A Tukey test (15) was used to examine differences between means.

Table 1. Characteristics of the Study Group

$\begin{array}{lc}\text { Maternal race } & 20 \\ \text { White } & 1 \\ \text { Black } & 2 \\ \text { Asian American } & 2 \\ \text { Mexican American } & 26.10 \pm 3.64^{1} \\ \text { Maternal age } & 2.84 \pm 1.43 \\ \text { Gravida } & 2.48 \pm 1.19 \\ \text { Parity } & 3575 \pm 465 \\ \text { Birth wt (g) } & 40.78 \pm 1.64 \\ \text { Gestational age } & 8.52 \pm 1.64 \\ \text { Apgar at 1 min } & 9.28 \pm 0.54 \\ \text { Apgar at } 5 \text { min } & \\ \text { Age in days at time of monitoring } & 4.88 \pm 2.15 \\ \text { 1 wk } & 30.88 \pm 6.02 \\ 1 \text { mo. } & 60.08 \pm 6.56 \\ 2 \text { mos. } & 88.92 \pm 7.94 \\ 3 \text { mos. } & 118.40 \pm 8.72 \\ 4 \text { mos. } & 170.88 \pm 8.70 \\ 6 \text { mos. }\end{array}$

${ }^{1}$ Mean \pm S.D.
A previous study demonstrated the variability among infants in incidence of breathing pauses (7). We therefore selected the Spearman rank order correlation to examine in data from all infants whether breathing pauses at one age or in one state predicted those at other ages and in other states. To answer the question of which variable(s) best predicted the density of total breathing pauses at 2 and 3 months of age, we submitted the data, supplemented with both the median and interquartile range of staterelated respiratory rates for each infant, to a multiple regression program. Variables considered as potential predictors were QS, AS, IN, and awake apnea densities, median respiratory rates, and respiratory variability as measured by the interquartile range. Breathing pause duration categories entered as independent variables were between 2 and $5 \mathrm{sec}, \geq 6 \mathrm{sec}$ duration, and $\geq 10 \mathrm{sec}$ duration. Dependent variables were total apnea $\geq 2 \mathrm{sec}, \geq 7 \mathrm{sec}$, and $\geq 10 \mathrm{sec}$. When appropriate, a square root transformation was performed to normalize the data. Finally, paired $t$ tests were used to compare mean densities of breathing pauses during sleep states and comparison of pauses of short, medium, and long durations.

\section{RESULTS}

\section{DENSITY OF BREATHING PAUSES}

Two to $5 \mathrm{Sec}$ Duration. Pauses of this length were extremely common during the first 6 months of life (Fig. 2). During the newborn period, a density score of 100 was observed in QS, indicating that on the average each min of the recording had one breath-to-breath interval of this length. Between 3 and 6 months of age, each min of the recording contained 2 to 3 breathing pauses of this duration. In spite of the apparent differences in the figure, due to considerable variability among infants, QS density scores obtained during the first 4 months of life could not be

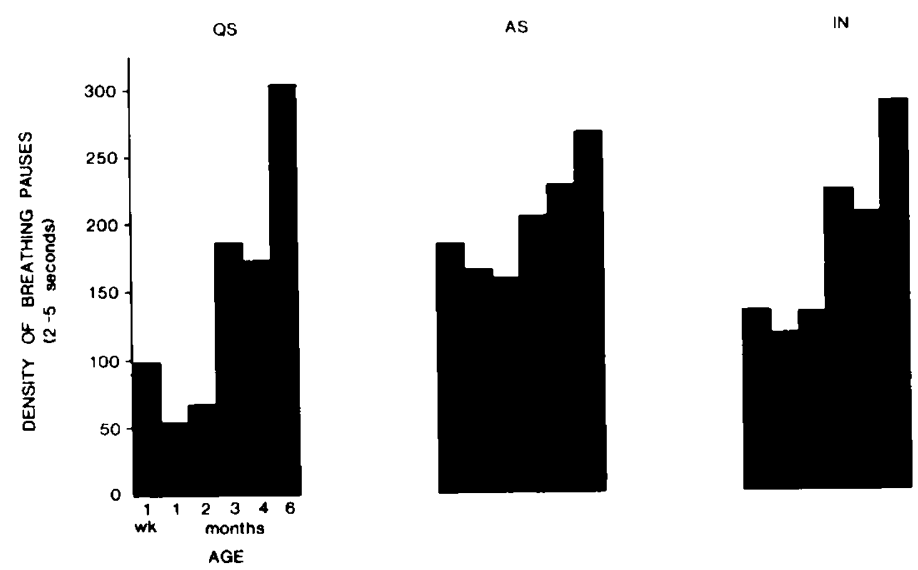

Fig. 2. Density of breathing pauses between 2 and $5 \mathrm{sec}$ (ordinate) in QS, AS, and IN, between I wk and 6 months of age ( abscissa). Profound increase of such pauses at 3 months of age, especially in QS

\section{MEASUREMENT OF BREATHING PAUSES}

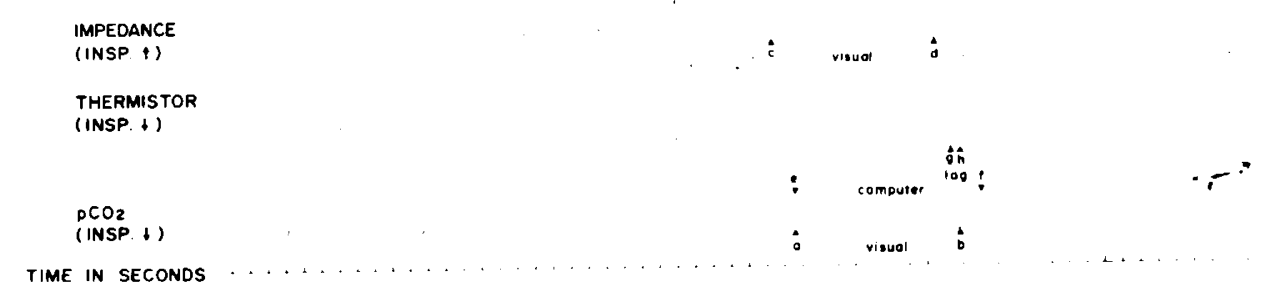

Fig. I. In a previous study (6), apneas were identified through visual inspection of three respiratory tracings. The intervals a-b in the pCO.: tracing and $\mathrm{c}-\mathrm{d}$ in the impedance tracing had to be equal to or exceed $6 \mathrm{sec}$. Computer identification of breathing pauses involved measurement between points $e$ and $f$. The latter interval is approximately $l \mathrm{sec}$ longer than the former. The interval g-h reflects the lag time between the respiratory signal based on a nasal thermistor and the $\mathrm{pCO}:$ signal. 
differentiated, but the score obtained at 6 months of age was significantly elevated compared to the first 2 months of life.

The AS density score was 200 in the newborn period and changed less than did the QS score during subsequent ages. The age trend was identical to that observed during QS, with only the 6 months score being significantly elevated compared to the score obtained at the remaining ages. Densities of breathing pauses in IN were most comparable to those seen in QS.

Six to $9 \mathrm{Sec}$ Duration. A plot of density scores is provided in Figure 3. The number of the ordinate is reduced by a factor of ten. In the newborn period, an average of $15 \%$ of QS min contained a breathing pause of this length, which is equivalent to approximately once every sixth QS min. Again, variability among infants was large, and none of the differences between the means at the various ages studied was significant.

The AS density score was $25 \%$ in the newborn period, indicating that on the average every fourth min of AS contained a breathing pause of this duration. This density score is significantly higher than those seen at 2 and 6 months of age. The IN score resembled that of QS in the newborn period, but that of AS at subsequent ages.

Equal to or Longer than $10 \mathrm{Sec}$. Apnea of this duration were more common during the first wk of life than at subsequent ages, as previously reported (6). In the newborn period, they were observed in approximately $4 \%$ of the QS $\mathrm{min}, 8 \%$ of AS min, and $5 \%$ of IN min (Fig. 4). A significant age trend was restricted to AS where the newborn density score was significantly elevated compared to all other ages.

\section{SLEEP STATE COMPARISONS}

Short breathing pauses ( 2 to $5 \mathrm{sec}$ ) during QS were less common than during AS for the first 2 months of life; thereafter, the density scores in these sleep states could not be differentiated. Breathing pauses between 6 and $10 \mathrm{sec}$ were significantly more common in

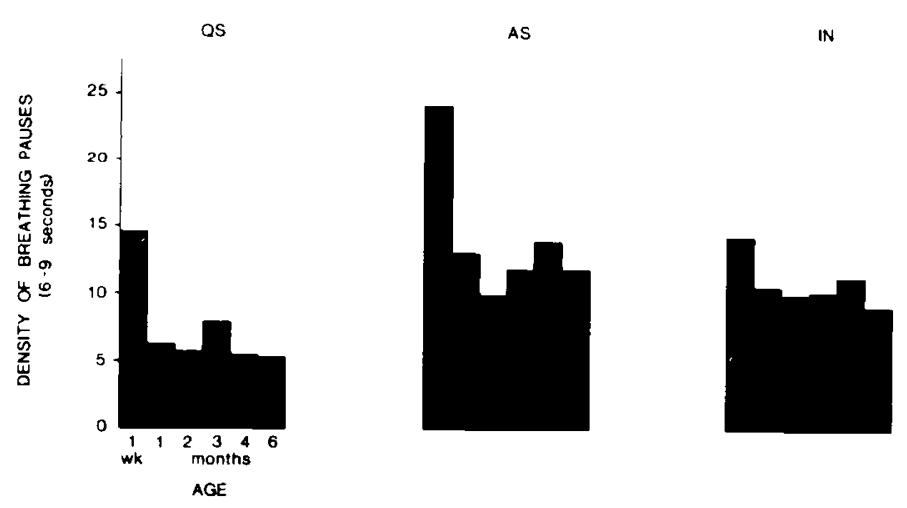

Fig. 3. Density of breathing pauses between 6 and 9 seconds (ordinate), as a function of age (abscissa). Only the AS density at one wk of age was significantly elevated compared to later ages.
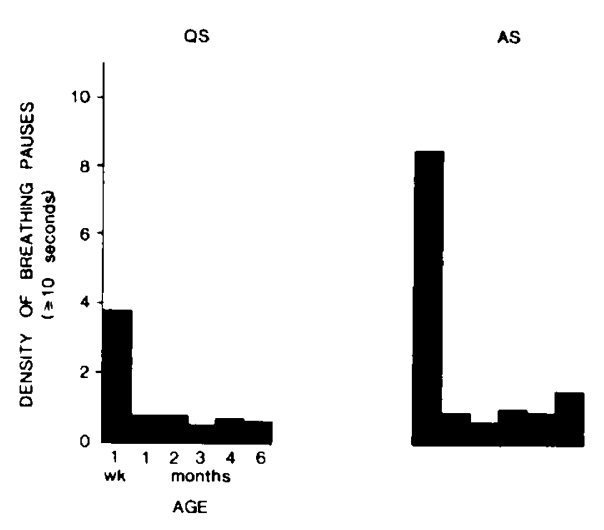

IN

Fig. 4. Density of breathing pauses equal to or longer than $10 \mathrm{sec}$. Elevated number of these apnea characterized the first wk of life.
AS at every age examined. Finally, no sleep state-related differences were observed in long apnea ( $\geq 10 \mathrm{sec}$ ).

A high-density score in short respiratory pauses during QS was correlated with a high score in AS at every age except one month. QS and IN density scores were significantly correlated throughout the entire age span, as were AS and IN density scores. Significant correlation coefficients were found in pauses equal to or longer than 6 sec obtained in every sleep state at every age. Finally, short and longer apnea were significantly correlated in every sleep state and at every age $(P<0.01)$.

\section{THE RELATIONSHIP BETWEEN APNEA IN THE NEWBORN PERIOD AND SUBSEQUENT AGES}

Results of multiple regression analysis indicated that none of the variables recorded during the first wk of life proved to be useful in predicting total apnea density of any duration category between the ages of 1 and 3 months. In one instance, the value of $R$ was in excess of 0.65 , with $R^{2}$ being 0.48 , a value of questionable significance (Table 2).

In contrast, from the recordings at 1 month, it became possible to predict total breathing pauses at 2 and 3 months of age. Only those instances in which a variable explained more than $60 \%$ of the variance were included, and in one case, only one variable was responsible for this percentage. All breathing pauses at 2 months of age were best predicted by one month AS breathing pauses in excess of $6 \mathrm{sec}$ duration, and at 3 months of age, they were predicted by 1 month AS breathing pauses in excess of 6 and $9 \mathrm{sec}$ duration (Table 2). In other words, comparatively long AS breathing pauses predicted total densities at 2 months of age, whereas short and long IN pauses predicted those at 3 months of age. The pauses in excess of 6 and $10 \mathrm{sec}$ duration in the 1,2 , and 3 months recordings could not be forecast. Furthermore, respiratory rates and variability never entered as significant variables.

\section{COMPARISON WITH PREVIOUS STUDIES}

To compare the data presented here with studies reported by others based on 1 or $2 \mathrm{hr}$ of recording, density scores at 3 months of age were recomputed based on the first $2 \mathrm{hr}$ of monitoring (Table 3). Most striking is the discrepancy between scores based on length of recording. In AS, twice as many pauses were counted when densities were based on $12 \mathrm{hr}$ of monitoring compared to 2 hr. In QS, that discrepancy rose to six times.

\section{DISCUSSION}

A previous study showed that central apnea between 6 and 15 sec are an integral part of normal respiratory development (7). The data presented in this study amplify this message and show in addition that shorter apnea are abundant in recordings of

Table 2. Prediction of apnea at subsequent ages; results of multiple regression analysis

\begin{tabular}{|c|c|c|c|}
\hline$R$ & $R^{2}$ & Independent variable & $\begin{array}{l}\text { Dependent vari- } \\
\text { able: total den- } \\
\text { sity of breathing } \\
\text { pauses } \geq 2 \text { sec }\end{array}$ \\
\hline \multicolumn{4}{|l|}{ At $\perp \mathbf{w k}$} \\
\hline 0.426 & 0.182 & Awake pauses $\geq 6 \mathrm{sec}$ & \\
\hline 0.561 & 0.314 & QS pauses $2-5 \mathrm{sec}$ & \\
\hline 0.694 & 0.481 & IN pauses $\geq 6 \mathrm{sec}$ & At 3 mos. \\
\hline \multicolumn{4}{|l|}{ At $1 \mathrm{mo}$} \\
\hline 0.782 & 0.611 & AS pauses $\geq 6 \mathrm{sec}$ & At 2 mos. \\
\hline \multicolumn{4}{|l|}{ At $1 \mathrm{mo}$. } \\
\hline 0.851 & 0.724 & IN pauses $2-5 \mathrm{sec}$ & At 3 mos. \\
\hline 0.890 & 0.792 & IN pauses $\geq 10 \mathrm{sec}$ & \\
\hline
\end{tabular}


Table 3. Apnea density scores at 3 months of age comparison with previous studies

\begin{tabular}{|c|c|c|c|c|}
\hline \multirow{2}{*}{$\begin{array}{c}\text { Studies } \\
\text { (Total apnea) }\end{array}$} & \multicolumn{2}{|c|}{$2-4 \mathrm{sec}$} & \multicolumn{2}{|c|}{$\geq 5 \mathrm{sec}$} \\
\hline & AS & QS & AS & QS \\
\hline
\end{tabular}

Present study: computer identified

$\begin{array}{rrrrr}2 \mathrm{hr} & 99.7 & 27.9 & 10.3 & 4.8 \\ 12 \mathrm{hr} & 190.8 & 182.8 & 24.8 & 11.7\end{array}$

Gould et al. (2): visually identified

$2-3 \mathrm{hr}$

\begin{tabular}{llll}
70.2 & 3.9 & 10.4 & 2.5 \\
\hline
\end{tabular}

normal infants during the first one-half year of life. Mean QS respiratory rates at 3 months of age, between 10:00 PM and 4:00 $\mathrm{AM}$, were found to be 25 breaths per min (8), indicating an interbreath interval of $2.4 \mathrm{sec}$. At 3 months of age, a sudden increase in apnea between 2 and $5 \mathrm{sec}$ therefore represents the developmental slowing of respiratory rates (6).

The impressive differences in apnea counts based on short and long recordings can be explained by two physiologic factors. The early portion of the recording, as is true of recording during a nap, is affected by events preceding monitoring, such as feeding and activity which reduce apnea density. Secondly, beyond the newborn period, slowing of autonomic function occurs during the early morning hr, resulting in longer breathing intervals (8). After adjustment for length of recordings, a significant difference remains in figures reported from different laboratories. This variance can be explained by technical factors such as differences in measurement techniques and analysis strategies.

Because apnea counts varied widely among infants, significant age trends were restricted to differences between the recordings at the youngest and oldest ages, a finding in agreement with those of Thoman et al. (13), who failed to observe significant age trends in infants between birth and 5 wk of age. Significant correlations in all sleep states between short and long apnea counts reported here were also found by the same investigators (13).

The stepwise discriminate analysis showed that apnea counts during the newborn period could not reliably identify infants with large numbers of apnea at subsequent ages. At 1 and 2 months of age, the predictive power of apnea counts increased significantly.

In light of the abundance of short breathing pauses and the variability among normal infants recorded under similar conditions, attaching pathologic significance to breathing pauses must be done with caution. The length of recording now must be considered as an additional source of variance.

\section{CONCLUSION}

Short respiratory pauses between 2 and $5 \mathrm{sec}$ were abundant, whereas apnea between 6 and 9 sec must be considered normal.
Apnea in excess of $10 \mathrm{sec}$ were common during the first wk of life, especially during AS, but became infrequent at later ages. Three additional features deserve mention. First, during early infancy, there was considerable variability in apnea densities among infants. Second, recording duration substantially affected the results. Finally, apnea at later ages could not be reliably predicted from recordings during the first wk of life.

\section{REFERENCES AND NOTES}

1. Beckwith, J. B.: Sudden infant death syndrome Curr. Probl. Pediatr., 3: I (1973).

2. Gould, J. B., Lee. A. F. S., James. O., Sander, L., Teager. H., and Fineberg. N. The sleep state characteristics of apnea during infancy. Pediatrics. 59: 182 (1977).

3. Guilleminault, C., Peraita, R., Souquet, M., and Dement, W. C.: Abnormal polygraphic findings in near miss infants for sudden infant death syndrome. Lancet, 1: 1326 (1976).

4. Harper, R. M., Sclabassi, R. J., and Estrin, T.: Time series analysis and sleep research. IEEE Trans. Automatic Control AC-19. 6: 932 (1974).

5. Hofmann, E., Havens, B., Geidel, S., Hoppenbrouwers, T., and Hodgman. J. E.: Long-term, continuous monitoring of multiple physiological parameters in newborn and young infants. Acta Pediatr. Scan. Suppl., 266: 5 (1977)

6. Hoppenbrouwers, T., Harper, R. M., Hodgman, J. E., Sterman, M. B.. and McGinty. D. J.: Polygraphic studies of normal infants during the first six months of life. II. Respiratory rate and variability as a function of state. Pediatr. Res., 12: 120 (1978).

7. Hoppenbrouwers. T. Hodgman, J. E., Harper, R. M., Hofmann, E., Sterman, M B., and McGinty. D. J.: Polygraphic studies of normal infants during the first six months of life. III. Incidence of apnea and periodic breathing. Pediatrics, 60: 418 (1977).

8. Hoppenbrouwers, T., Jensen, D., Hodgman, J. E.. Harper, R. M., and Sterman. M. B.: Respiration during the first six months of life in normal infants. II. The emergence of a circadian pattern. Neuropaediatrie. 10: 264 (1979).

9. Mason. J., Harper, R. M., and Pacheco, R.: Analysis of respiratory data during sleep and waking. Proc. Dig. Equip. Comput. Users Soc.. 1: 567 (1974)

10. Steinschneider, A.: Prolonged apnea and the sudden infant death syndrome: clinical and laboratory observations. Pediatrics, 50: 646 (1972).

11. Steinschneider, A.: Prolonged sleep apnea and respiratory instability. A discriminative study. Pediatrics, 59 (Suppl. 6): 962 (1977).

12. Steinschneider. A., and Rabuzzi. D. D.: Apnea and airway obstruction during feeding and sleep. Laryngoscope, 9: 1359 (1976)

13. Thoman. E. B., Freese. M. P., Becker, P. T., Acebo, C., Morin. V. N., and Tynan W. D.: Sex differences in the ontogeny of sleep apnea during the first year of life. Physiol. Behav., 20:699 (1978)

14. Usher, R., and McLean. F.: Intrauterine growth of live-born Caucasian infants at sea level: standards obtained from measurements in seven dimensions of infants born between 25 and 44 weeks gestation. J. Pediatrics, 74: 901 (1969).

15. Winer. G. J.: Statistical Principles in Experimental Design. (McGraw-Hill. New York. 1962).

16. The authors thank B. Havens, E. Hofmann, and S. Geidel for the development of the monitoring program and their contribution to the data collection. We also acknowledge the contribution of Jerry Mason and Debra Jensen

17. Requests for reprints should be addressed 10: Toke Hoppenbrouwers. Ph.D. Director, Sudden Infant Death Syndrome (SIDS) Research Project, Room 4L40B, Women's Hospital. LAC/USC Medical Center, 1240 North Mission Road, Los Angeles. CA 90033 (USA).

18. This research was supported by the NIHCHD Contract NOI-HD-2-2777 and HD 4-2810. Computing assistance was obtained from the Health Sciences Computing Facility, UCLA, supported by the NIH Special Research Resources Grant RR-3.

19. Received for publication August 14, 1979

20. Accepted for publication January 29, 1980. 